\title{
CISTO DE COLÉDOCO: RELATO DE CASO E REVISÃO DA LITERATURA
}

\section{Choledochal cyst: case report and literature review}

\author{
JF GANDOLFI , FR CARVALHO-NETO, H GANDOLFI, AC PAULA, \\ RPA GUIRALDO, Guilherme de Campos MARINO
}

ABCDDV/543

Gandolfi JF, Carvalho-Neto FR, Gandolfi H, Paula AC, Guiraldo RPA, Marino GC. Cisto de colédoco: relato de caso e revisão da literatura ABCD Arq Bras Cir Dig 2007; 20(2):130-3.

RESUMO - Introdução - Cistos de colédoco são dilatações congênitas dos ductos biliares, tanto intra quanto extra-hepáticas. É incomum com incidência estimada em 1:100.000 até 1:150.000 nascidos vivos nos países ocidentais. Relato do caso - Mulher de 36 anos com história de icterícia, colúria e massa palpável em hemiabdome direito há 15 dias, negava acolia fecal, febre e emagrecimento. Ao exame físico apresentava ictérica e presença de uma massa palpável e indolor em hipocôndrio direito com cerca de $25 \mathrm{~cm}$ de diâmetro, sem outras alterações. Os exames laboratoriais evidenciaram aumento de enzimas canaliculares, hepatocíticas e bilirrubinas. CA 19-9, alfa-feto proteína e CEA foram normais. Exames de imagem do abdome mostraram massa de conteúdo cístico em topografia de colédoco e cabeça de pâncreas. Operada por laparotomia, foi evidenciado cisto de colédoco, classificação de Todani tipo I. A vesícula biliar foi ressecada juntamente com a porção distal do cisto e anastomose biliodigestiva em Yde-Roux foi realizada entre a alça de jejuno e porção proximal do cisto. A evolução pós-operatória foi tumultuada com sangramento da anastomose e necessidade de reoperações para conter sangramento e complicações conseqüentes. Conclusão - Os cistos de colédoco são entidades raras e têm múltiplos aspectos em sua forma. O diagnóstico é facilmente feito pelos métodos de imagem correntes, contudo seu tratamento é difícil, por vezes de grande magnitude, e deve ser individualizado.

DESCRITORES - Ducto biliar comum. Cisto de colédoco.

\section{INTRODUÇÃO}

Cistos de colédoco são dilatações congênitas dos ductos biliares, tanto intra quanto extra-hepáticas ${ }^{1}$. É incomum com incidência estimada em 1:100.000 até 1:150.000 nascidos vivos nos países ocidentais ${ }^{1,2,3}$, e 3 vezes mais freqüente no sexo feminino. Pode apresentar-se em qualquer idade, sendo que $2 / 3$ dos casos são diagnosticados durante a primeira década de vida ${ }^{1}$. Nenhuma hereditariedade ou predisposição genética foi estabelecida, apesar de casos de cisto no ducto biliar serem relatados em membros de uma mesma família.

Os ductos colédoco e pancreático formam um canal comum fora do duodeno que permite o refluxo de suco pancreático para o sistema biliar, ocasionando aumento da pressão intra-ductal e inflamação, que em conjunto, levariam à dilatação ${ }^{1,2,4}$.

A tríade clássica é composta por dor abdominal, icterícia e massa palpável. O cisto pode ser visualizado por vários métodos complementares ${ }^{2}$. A sua grande complicação é a alta taxa de malignização (até $30 \%)^{12}$.

Trabalho realizado na Disciplina de Cirurgia Geral (Enfermaria de Vias Biliares) do Departamento de Cirurgia Geral da FAMERP - Faculdade de Medicina de São José do Rio Preto, São José do Rio Preto, SP, Brasil Endereço para correspondência: Guilherme de Campos Marino, e-mail:guilhermemarino@yahoo.com.br

\section{RELATO DO CASO}

Mulher de 36 anos foi admitida no hospital, com história de icterícia, colúria e massa palpável em hemiabdome direito há 15 dias. Negava acolia fecal, febre e emagrecimento. Ao exame físico apresentava ictérica e presença de uma massa palpável e indolor em hipocôndrio direito com cerca de 25 $\mathrm{cm}$ de diâmetro, sem outras alterações.

Os exames laboratoriais evidenciaram aumento de enzimas canaliculares, hepatocíticas e bilirrubinas (FA: 334ng/dL; GGT: 152ng/dL; AST: 81ng/dL;ALT: 170ng/dL e BT: 2,6ng/dL, BD: 2,2ng/dL). CA 19-9, alfa-feto proteína e CEA foram normais. Tomografia computadorizada de abdome mostrou uma massa de conteúdo cístico em topografia de colédoco e cabeça de pâncreas. A colangiorressonância magnética de abdome evidenciou um cisto de grandes dimensões em topografia de colédoco (Figuras 1 e 2), ausência de dilatação de vias biliares intra-hepáticas e pâncreas normal.

A paciente foi submetida à intervenção cirúrgica para ressecção do cisto por incisão subcostal bilateral. No intraoperatório, foi evidenciado cisto de colédoco, classificação de Todani tipo I (Figura 3), de grandes dimensões $(25 \mathrm{~cm}$ de comprimento x $10 \mathrm{~cm}$ de largura) tendo sido afastada malignidade pela biópsia de congelação e, posteriormente, confirmado ser somente cisto de colédoco pelo estudo anatomopatológico. O conteúdo do cisto foi aspirado com agulha fina (Figura 4) e era de aspecto biliar. 


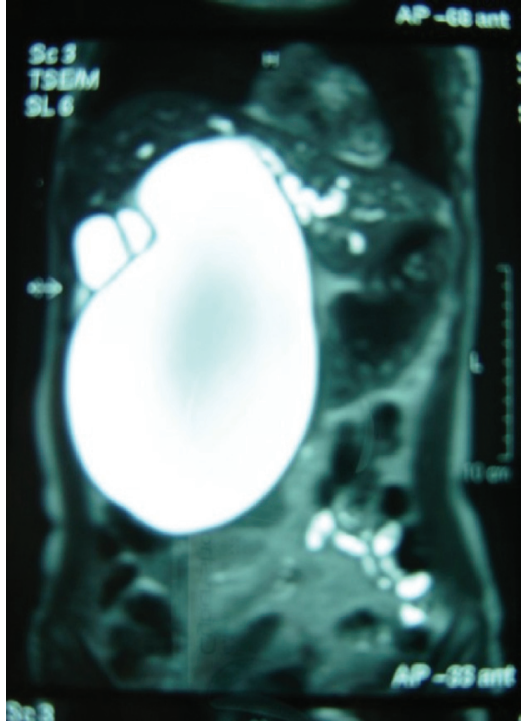

FIGURA 1 - Cisto em topografia de vias biliares extra-hepáticas

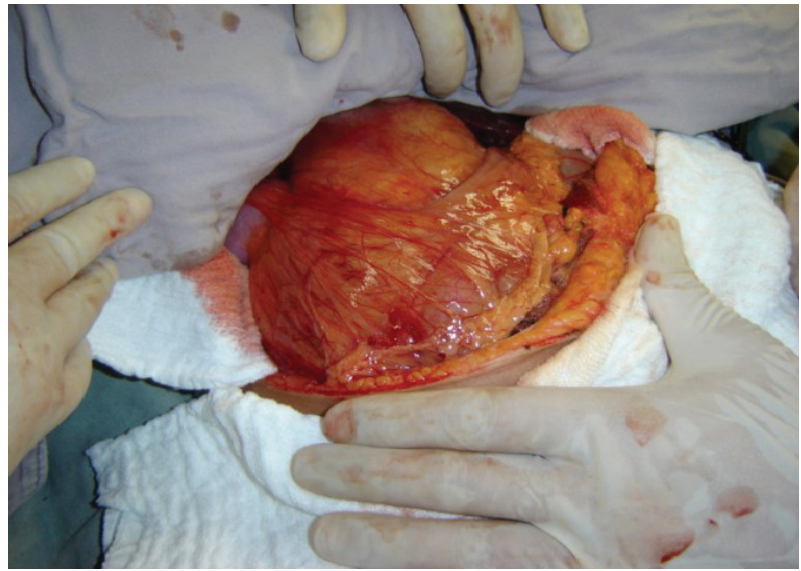

FIGURA 3 - Cisto de colédoco Todani I

A vesícula biliar foi ressecada juntamente com a porção distal do cisto e anastomose biliodigestiva de $2 \mathrm{~cm}$ em Y-de-Roux foi realizada entre a alça de jejuno e porção proximal do cisto em plano único, com PDS 4-0. Não foi possível ressecar a porção proximal do cisto, pois os ductos hepáticos direito e esquerdo não estavam dilatados e seus óstios distavam $7 \mathrm{~cm}$, impossibilitando a união deles ou a realização de duas anastomoses biliodigestivas devido ao risco de estenose. Foi realizada revisão da hemostasia e posicionado um dreno de Wattermann próximo à anastomose exteriorizado através da pele.

A paciente evoluiu estável no pós-operatório, em unidade de terapia intensiva. Entretanto, no $5^{\circ}$ dia de pósoperatório, evoluiu com choque hipovolêmico e presença de sangue vivo com coágulos exteriorizados através do dreno. Foi realizada nova revisão cirúrgica que evidenciou grande hematoma de retroperitônio, não sendo possível localizar o sítio do sangramento. Foi realizado curativo de Mickulicz com quatro compressas na cavidade e posterior síntese da parede abdominal. No pós-operatório imediato,

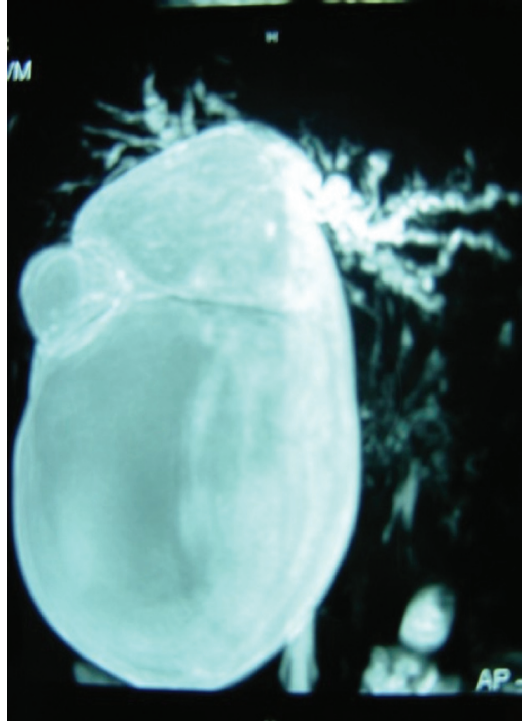

FIGURA 2 - Cisto em topografia de vias biliares extra-hepáticas

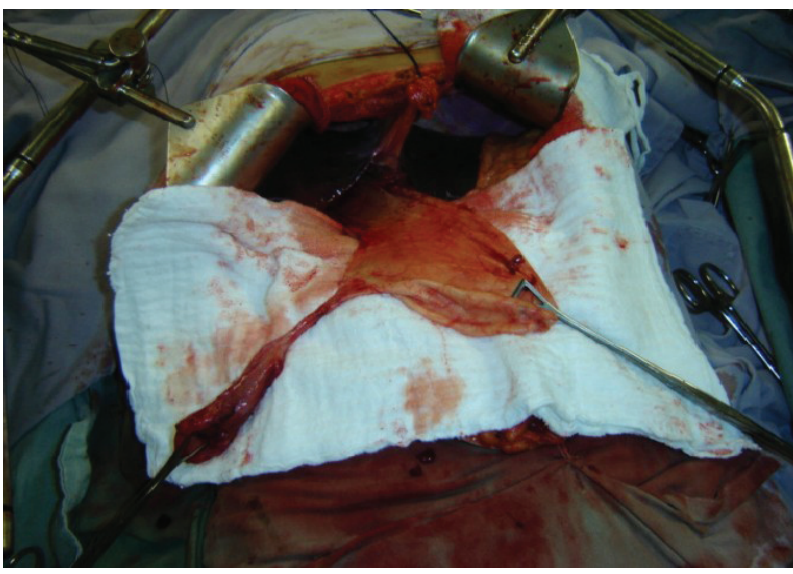

FIGURA 4 - Cisto e vesícula biliar após ter sido aspirado seu conteúdo

ela foi submetida à arteriografia de tronco celíaco, sendo evidenciado sangramento ativo da artéria gastroduodenal que foi embolizada com Gelfoam e mola de Gianturco-Wallace, com sucesso. Em 48 horas, foi relaparotomizada para retirada das compressas da cavidade e fechamento da aponeurose sem tensão. Evoluiu com síndrome compartimental abdominal, sendo necessária nova intervenção cirúrgica, que evidenciou fístula da anastomose biliodigestiva de 1 $\mathrm{cm}$. Foi realizada síntese apenas da pele e colocado dreno de Kher no interior da fístula, sendo exteriorizado através da pele. A paciente evoluiu com deiscência de anastomose, sendo optado pela cicatrização por segunda intenção, com direcionamento da fístula biliar para a pele. Evoluiu com sepse, traqueostomizada, em uso de drogas vasoativas, sem evidências de coleções intra-abdominais e antibioticoterapia de largo espectro.

\section{DISCUSSÃO}

A maior prevalência destes cistos é observada em países 
asiáticos, especialmente no Japão que apresenta incidência de 1:1000. A razão para essa maior prevalência é desconhe$\mathrm{cida}^{4}$. Na atualidade há aumento de seu diagnóstico devido ao aperfeiçoamento das técnicas de imagem não-invasiva da árvore biliar.

Os cistos biliares são classificados de acordo com a localização, extensão e forma. Em 1959 Alonso-Lej $^{5}$ propuseram classificação que englobava apenas cistos biliares extra-hepáticos. Essa classificação foi modificada por Todani em $1977^{6}$, que incorporou as dilatações intrahepáticas ${ }^{1,4}$.

Os cistos do tipo I são dilatações fusiformes ou císticas da árvore biliar extra-hepática, sendo os mais comuns $(50 \%)$ o encontrado no caso relatado.

Os cistos do tipo II são divertículos saculares do canal biliar extra-hepático e correspondem a menos de $10 \%$ dos cistos.

O tipo III é dilatação do canal biliar dentro da parede do duodeno, também chamada de coledococele sendo responsável por menos de $10 \%$ dos casos.

Já os cistos do tipo IV, segundo em freqüência (35\%), correspondem a dilatações císticas da árvore biliar intra e extra-hepática.

O tipo $\mathrm{V}$ corresponde a cistos intra-hepáticos (doença de Caroli) $)^{3}$.

A dilatação no cístico pode ocorrer através dos ductos biliares, extra e intra-hepáticos, e assim "cisto no ducto biliar" e "doença cística no trato biliar" são termos semanticamente mais apropriados para essa condição.

Até o momento não existe etiologia claramente definida para explicar a formação dos cistos de colédoco. Todavia, existem hipóteses que sustentam, em parte, sua formação. A hipótese mais provável é a teoria do longo canal comum maior que $15 \mathrm{~mm}$, sugerida por $\mathrm{Babbit}^{7}$,segundo a qual os ductos colédoco e pancreático formam um canal comum fora do duodeno (junção pancreato-biliar anômala) que permite o refluxo de suco pancreático para o sistema biliar, ocasionando aumento da pressão intra-ductal e inflamação que, em conjunto, levariam à dilatação ${ }^{1,2,4}$.

Por outro lado, junções pancreato-biliares anômalas são detectadas em $60 \%-90 \%{ }^{1,4}$ dos pacientes, sugerindo que essa má-formação não pode ser unicamente responsabilizada pelas dilatações. Além disso, essa teoria não explica cistos intra-hepáticos, onde o refluxo de suco pancreático é improvável ${ }^{1}$. Outros fatores possivelmente envolvidos são a obstrução ductal, função anormal do esfíncter da ampola hepatopancreática, agangliose distal do ducto biliar comum ${ }^{4}$. Esta última pode resultar em inervação autonômica inadequada, levando a obstrução funcional e dilatação proximal análogo à acalasia ou megaesôfago chagásico ou doença de Hirschsprung no cólon.

A possibilidade de etiologia viral deve ser considerada depois da detecção de um retrovírus RNA em tecidos de pacientes com cistos no ducto biliar comparado com pacientes controles ${ }^{14}$. A hipótese de como o vírus poderia contribuir com a fisiopatologia é de que dispararia resposta imune podendo levar a aganglionose.

Como já foi citado anteriormente, a associação de longo canal comum com junção anômala pancreatobiliar favorece o refluxo de suco pancreático na árvore biliar que causa danos às junções intercelulares do epitélio biliar e fibrose da parede. Episódios recorrentes de inflamação resultam em fraqueza e adelgaçamento da parede do ducto biliar, que pode resultar em expansão/dilatação, dando origem aos $\operatorname{cistos}^{1,4,8,9}$.

A apresentação clínica dos pacientes depende da faixa etária. Aqueles que apresentam o cisto de colédoco durante a infância têm sinais e sintomas de obstrução biliar (icterícia, fezes acólicas, vômitos, irritabilidade e retardo de crescimento) $)^{1,2,3,4,10,11}$. Pacientes adultos apresentam como sintoma mais comum dor abdominal - ausente no caso relatado. A tríade clássica composta por dor abdominal, icterícia e massa palpável é encontrada em torno de $20 \%$ $25 \%$ dos pacientes (versus $85 \%$ na população pediátrica) ${ }^{2}$ e estava também ausente na paciente relatada.

Exames laboratoriais, como enzimas hepáticas, canaliculares e amilase podem apresentar-se alterados, porém não são considerados diagnósticos para os cistos de colédoco; valores anormais refletem complicações da doença.

Devido à sua raridade os cistos de colédoco são suspeitados ou diagnosticados em exames de imagem hepatobiliares, em geral solicitados quando o paciente apresenta queixa de desconforto abdominal em andar superior de abdome $e^{1,2,3,4,8,10}$.

À ultra-sonografia o cisto se apresenta como massa cística, preenchida por conteúdo fluido, podendo ser delimitada e demonstrada as relações com outros órgãos, além de sinais inflamatórios e cálculos. A tomografia computadorizada é excelente método para delimitar anatomia no pré-operatório (relações com duodeno, cabeça do pâncreas e junção pancreatobiliar). A cintilografia de vias biliares é feita em crianças cujo diagnóstico diferencial envolve atresia biliar. $\mathrm{O}$ fígado capta os radionúcleos e secreta-os na bile, que por processo de estase se acumula no cisto. A colangiografia endoscópica retrógrada é o exame de escolha, pois fornece estudo detalhado da anatomia do trato biliar e junção pancreatobiliar sendo, contudo, método invasivo e não isento de riscos. A vantagem da colangiorressonância é que se trata de método não-invasivo, porém não fornece imagens tão boas quanto a endoscópica ${ }^{2,4,14}$.

Complicações podem ocorrer entre $60 \%$ e $80 \%$ dos pacientes, destacando-se a perfuração e peritonite, colelitíase, colangite, cirrose biliar, hipertensão portal e malignização $0^{2,3,4,12}$. O risco de transformação maligna varia de $2,5 \%$ a $28 \%$, dependendo do autor e da série estudada. O tipo histológico mais comum é o colangiocarcinoma (pode aparecer em qualquer tipo de cisto, porém os tipos I e IV estão associados a maior incidência) ${ }^{12}$ sendo que o tumor pode se localizar tanto no interior do cisto quanto em outros locais do sistema hepatobiliar. A incidência aumenta com a idade e a média de idade que ocorre o aparecimento de malignidade dos cistos biliares é de 32 anos (duas décadas antes da população geral) ${ }^{13}$.

O tratamento é diferenciado para os diferentes tipos de cistos; o procedimento de escolha para os cistos tipo I e II é a sua completa excisão, associada à colecistectomia e 
reconstrução feita por hepatojejunostomia em Y-de-Roux, conduta cirúrgica adotada no caso relatado. $\mathrm{O}$ tratamento do tipo III é mais controvertido, pois não há consenso, uma vez que esse tipo é raro. O padrão tem sido sua excisão com esfincteroplastia. O tratamento dos cistos do tipo IV também é controverso, podendo ser realizada tanto a excisão total quanto a hepatectomia parcial ${ }^{1,2,3,4,13}$.

\section{CONCLUSÃO}

Os cistos de colédoco são entidades raras e têm múltiplos aspectos em sua forma. O diagnóstico é facilmente feito pelos métodos de imagem correntes, contudo seu tratamento é difícil, por vezes de grande magnitude e deve ser individualizado.

Gandolfi JF, Carvalho-Neto FR, Gandolfi H, Paula AC, Guiraldo RPA, Marino GC. Choledochal cyst: case report and literature review. ABCD Arq Bras Cir Dig 2007; 20(2):130-3.

ABSTRACT - Background - Choledochal cysts are congenital dilations of biliary ducts, being either intra or extra-hepatic. It is uncommon, having an estimated incidence of 1:100.000 to 1:150.000 born alive in western countries. Case report - Thirty six-year-old female was attended with a history of jaundice, coluria and palpable mass in the right hemiabdomen for 15 days, denying fecal acholia, having fever and weight loss. During physical examination the patient presented jaundice and a painless palpable mass in the right hypochondrium, having an approximate diameter of $25 \mathrm{~cm}$, without any other alterations. Laboratory exams demonstrated an increase in canicular, hapatocytic and bilirubin enzymes. CA 19-9, alfafetoprotein and CEA showed normal levels. Abdominal image exams revealed a cystic content mass in the choledochal and head of the pancreas. A choledochal cyst was revealed after laparotomy, being classified as type I, with regards to Todanis' classification. The gallbaldder was ressected jointly with the distal portion of the cyst. Biliodigestive anastomosis in Y of Roux was performed between the jejunum loop and distal portion of the cyst. Postoperative evolution was tardied by bleeding from anastomosis and the patient was reoperated to contain bleeding and further complications. Conclusion - Choledochal cysts are rare entities, having multiple aspects regarding there shape and form. Diagnosis is easily done using image methods. However its treatment is difficult, sometimes being of great magnitude, therefore requiring individual treatment.

HEADINGS - Common bile duct. Choledochal cyst.

\section{REFERÊNCIAS}

1.1. Alonso-Lej F, Rever W, Pessagno D. Congenital choledochal cysts, with report of 2, and an analysis of 94 cases. Int Surg. 1959;108:1-30.

2. Atkinson H,Fischer C,de Jong C,Madhavan KK,Parks RW,Garden OJ.Choledochal cysts in adults and their complications.HPB Surg 2003;5:105110.

3. Babbit DP. Congenital choledochal cysts:new etiological concept based on anomalous relantionships of the common bile duct and pancreatic bulb. Ann Radiol (Paris). 1969;12:231-40.

4. Chaudhary A, Dhar P, Sachdev A, Kumar N, Vij JC, Sarin SK, et al. Choledochal cysts-differences in children and adults. Br J Surg. 1996;83:186-8.

5. Coelho JCU. Gastroenterologia. 1996;2.

6. Irie H, Honda H, Jimi M, Yokohata K, Chijiwa K, Kuroiwa T, et al. Value of MR cholangiopancreatography in evaluating choledochal cysts. AJR Am J Roentgenol. 1998;171:1381-5.

7. Iwai N, Yanagihara J, Tokiwa K, Shimotake T, Nakamura K. Congenital choledochal dilatation with emphasis on pathophysiology of the biliary tract. Ann Surg. 1992;215:27-30.

8. Nagorney DM. Bile duct cysts in adults. In: Blumgart LH, Fong Y, editors. Surgery of the liver and biliary tract. 3rd ed. London: WB Saunders: 2000. v.2, p.1229-44.
9. Nicholl M,Pitt HA, Wolf P.,Cooney J,Kalayoglu M,Shilyansky J et al. Choledochal cysts in western adults:complexities compared to children.J Gastrointest Surg 2004;8:245-252.

10. Soreide K, Korner H, Soreide JA. Bile duct cysts in adults. Br J Surg. 2004;91:1538-48.

11. Todani T, Watanabe Y, Narusue M, Tabuchi K, Okajima K. Congenital bile duct cysts: classification, operative procedures, and rewiew of thirty-seven cases including cancer arising from choledochal cyst. Am J Surg. 1977;134:2639.

12. Townsend CM. Sabiston - Tratado de cirurgia. 16 ed. 2003.

13. Tyler KL, Sokol RJ, Oberhaus SM, Le M, Kamer FM, Narkewicz MR et al. Detection of reovirus RNA in hepatobiliary tissues from patients with extrahepatic biliary atresia and choledochal cysts. Hepatology. 1998;27:1475-82.

14. Yamaguchi M.Congenital choledochal cyst.Analysis of 1433 patients in the Japanese literature.Am J Surg 1980;140:653-657.

Conflito de interesse: não há Fonte financiadora: não há Recebido para publicação em: 14/01/2007 Aceito para publicação em: 20/04/2007 